\title{
ANTECEDENTS AND CONSEQUENCES OF ACCOUNTING GOVERNANCE: AN EMPIRICAL STUDY OF PAPER MANUFACTURING BUSINESSES IN THAILAND
}

\author{
Phatcharee Prasong, Mahasarakham Business School, Mahasarakham University, Thailand \\ Phapruke Ussahawanitchakit, Mahasarakham Business School, Mahasarakham University, Thailand \\ Kesinee Muenthaisong, Mahasarakham Business School, Mahasarakham University, Thailand
}

dx.doi.org/10.18374/JIBE-13-3.13

\begin{abstract}
This research investigates the effects of accounting governance on goal achievement through the mediating influences of operational value increase, financial information reliability, and decision-making excellence through best accounting system as a moderator. Also, the associative roles of executive vision for long-term operation, morality culture, business survival awareness, stakeholder expectation, and environmental dynamism influence accounting governance is investigated through ethical climate as a moderator. Accounting governance consists of accounting standard concern, accounting practice disclosure, accounting ethics orientation, accounting reporting transparency, and social impact focus. Data were collected by survey questionnaires sent to the accounting executives of paper manufacturing businesses in Thailand and 131 completed questionnaires are used in the analysis. The results of OLS regression analysis show that accounting ethics orientation has a significant positive effect on financial information reliability and operational value increase, accounting reporting transparency has a significant positive effect on financial information reliability, and social impact focus has a significant positive effect on financial information reliability, operational value increase and decision-making excellence. Moreover, financial information reliability has positive relationships on operational value increase and decision-making excellence. Likewise, financial information reliability, operational value increase and decision- making excellence have positive impact on goal achievement. With respect to antecedent variables, executive vision for long-term operation, morality culture, stakeholder expectation and dimensions of accounting governance are positively significant except for business survival awareness and environmental dynamism. Surprisingly, there are very few studies showing a positive significant effect of both ethical climate and best accounting system as the moderating effect on relationships among dimensions of accounting governance, antecedents and consequences. Theoretical and managerial contributions are explicitly provided. A conclusion, suggestions, and directions for future research are highlighted.
\end{abstract}

Keywords: Accounting Governance, Accounting Standard Concern, Accounting Practice Disclosure, Accounting Ethics Orientation, Accounting Reporting Transparency, Social Impact Focus, Operational Value Increase, Financial Information Reliability, Decision-Making Excellence, Goal Achievement, Executive Vision for long-Term Operation, Morality Culture, Business Survival Awareness, Stakeholder Expectation, Environmental Dynamism, Ethical Climate, Best Accounting System 